\title{
Convergence of Energy Carbon Emission Efficiency: Evidence From Manufacturing Sub-sectors in China
}

Dongdong Liu ( $\sim$ liudongdong@sdnu.edu.cn )

Shandong Normal University https://orcid.org/0000-0002-4919-7938

\section{Research Article}

Keywords: Energy carbon emission efficiency, $\mathrm{CO} 2$ emission, Evolution trend, Convergence, Data envelopment analysis

Posted Date: November 16th, 2021

DOl: https://doi.org/10.21203/rs.3.rs-898215/v1

License: (9) This work is licensed under a Creative Commons Attribution 4.0 International License. Read Full License

Version of Record: A version of this preprint was published at Environmental Science and Pollution Research on January 10th, 2022. See the published version at https://doi.org/10.1007/s11356-02218503-9. 


\title{
Convergence of energy carbon emission efficiency: evidence from manufacturing sub-sectors in China
}

\author{
Dongdong Liu \\ School of Economics, Shandong Normal University, Jinan, 250358, China
}

\begin{abstract}
With China's economy entering the stage of high-quality development, manufacturing energy carbon emission efficiency has become the focus of academic attention. Based on the panel data of China's manufacturing sub-sectors, this paper measures and analyzes the evolution trend of manufacturing energy carbon emission and its efficiency. On this basis, this paper uses coefficient of variation and convergence model to test the convergence of manufacturing energy carbon emission efficiency. The results show that China's manufacturing energy carbon emissions and its efficiency show an increasing trend. The coal was the main source of manufacturing energy carbon emissions. The manufacturing energy carbon emission efficiency does not exist $\sigma$ convergence, but exists $\beta$ convergence, and its convergence exists industry heterogeneity. The manufacturing energy carbon emission efficiency exits scale effect and technology effect, but not the effect of opening to the outside world and institutional effect, and its effect exists industry heterogeneity. By reducing carbon emissions, adopting differentiated policies, adjusting the industry scale, and enhancing the industry technology intensity, China's manufacturing can improve the energy carbon emissions efficiency and promote high-quality economic development.
\end{abstract}

Keywords Energy carbon emission efficiency - CO2 emission • Evolution trend $\cdot$ Convergence $\cdot$ Data envelopment analysis

\section{Introduction}

Since the reform and opening up, China has made great achievements in economy. China's gross domestic product was only RMB 367.87 billion in 1978, RMB 10028.81 billion in 2000 and RMB 99086.51 billion in $2019^{1}$. Meanwhile, it is faced with the problems of low resource utilization efficiency, increasing of energy consumption and carbon dioxide emissions. According to data of British Petroleum report ${ }^{2}$, China's carbon dioxide was 7710.1 million tonnes in 2009 and 9825.8 million tonnes in 2019, The average annual growth rate is $2.6 \%$ from 2008 to 2018 and $3.4 \%$ in 2019. China faces great pressure on carbon emission reduction. For one thing, although China's per capita carbon emission is lower, its total carbon emission ranks first in the world. At the 75th UN General Assembly, China has made clear that it will strive to reach the peak of carbon dioxide emissions by 2030 and achieve carbon neutrality by 2060 . Meanwhile, China will bring carbon peaking and carbon neutralization into the overall layout of ecological civilization construction. For another, China's economy is currently in a stage of high-quality development, and the transformation of economic development mode has become the focus of that. The extensive

\footnotetext{
Corresponding author: Dongdong Liu; Email: liudongdong@sdnu.edu.cn

1 Note: The data comes from National Bureau of Statistics.

Note: The carbon emissions above reflect only those through consumption of oil, gas and coal for combustion related activities, and are based on 'Default CO2 Emissions Factors for Combustion' listed by the IPCC in its Guidelines for National Greenhouse Gas Inventories (2006).
} 
growth mode of high input, high pollution and low efficiency cannot meet the requirements of high-quality development. Therefore, it should improve energy carbon emission efficiency for China. Improving energy carbon emission efficiency can not only reduce carbon emissions and achieve low-carbon economic development, but also ensure stable economic growth (Teng et al. 2017).

China's has become the largest manufacturing country in the world by virtue of the comparative advantages of low-cost supply of factors. According to world bank, in 2010, the added value of manufacturing industry in China surpassed that of the United States and became the largest manufacturing country. In 2005, the added value of China's manufacturing accounted for $11.6 \%$ of the added value in the whole world, rising to $24.8 \%$ in 2017 . With the unceasing development of the China's industry, manufacturing has become the main industry of energy consumption and carbon dioxide emissions in China. In 2015, manufacturing energy consumption accounted for $56.97 \%$ of total energy consumption in China, and carbon dioxide emissions accounted for $54.90 \%$ of China's total carbon emissions (Xie et al. 2018). Meanwhile, the proportions of value added of manufacturing is negatively correlated with carbon emissions since 2000 (Dong et al. 2020). Along with China's economy is in the stage of high-quality development, the environmental and resource constraints faced by manufacturing continue to strengthen. Manufacturing plays an important role in the national economy, which is the key to promote high-quality economic development. Therefore, it is of great theoretical and practical significance to study the energy carbon emission efficiency of manufacturing. Meanwhile, it provides experience for sustainable development of manufacturing in developing countries.

However, research on the measurement of energy carbon emission efficiency mainly uses the method including single factor. The above methods cannot fully reflect the impact of other production factors on carbon emission efficiency. Carbon emission efficiency refers to the ratio of production relations to achieve the minimum carbon dioxide emissions and the maximum economic output when the input of labor, capital and energy is no increasing ( $\mathrm{Li}$ et al. 2020). Moreover, the number of studies on manufacturing energy carbon emission efficiency in China are relatively few (Yang et al. 2015). And, there are differences in the factor endowments of China's manufacturing sub-sectors, which leads to the unbalanced development of manufacturing. Therefore, this paper studies the convergence of China's manufacturing energy carbon emission efficiency. It is of great significance for improving energy carbon emission efficiency and realizing high-quality development of manufacturing in China.

The purpose of this research is to explore the convergence of China's manufacturing energy carbon emission efficiency. First, this study calculates manufacturing carbon emission and analyzes its characteristics and sources. Second, this study calculates manufacturing energy carbon emission efficiency and analyzes its dynamic evolution trend. Third, this study uses coefficient of variation and convergence model to test the convergence of China's manufacturing energy carbon emission efficiency.

The rest of the paper is organized as follows. Section 2 reviews the relevant literature. Section 3 introduces the methodology and data. Section 4 presents the empirical results and discussion. Section 5 ends up with conclusions and policy implications.

\section{Literature review}

Research on the measurement of energy carbon emission efficiency mainly uses the method 
including single factor. The evaluation method of single factor efficiency includes carbon dioxide emissions per unit energy, energy consumption per unit GDP (Cheng et al. 2016; Pretis and Roser 2017). The above methods cannot fully reflect the impact of other production factors on carbon emission efficiency. Therefore, studies on the calculation of energy carbon emission efficiency have mainly used the data envelopment analysis (DEA) method, and malmquist index (Farrell 1957) is often used to measure efficiency (Hernández-Sancho et al. 2011; Wu and Li 2014; Zhao et al. 2019).

However, the efficiency including unexpected output cannot be reflected by the method of malmquist index. Therefore, the malmquist luenberger index (Chung et al. 1997) was used to measure the energy efficiency (Watanabe and Tanaka 2007). With the continuous improvement of the method, the malmquist luenberger index has the potential linear programming unsolved problem and the non-cyclical or transitive characteristics. Hence, Global malmquist luenberger index (Oh 2010) was used to measure carbon productivity. For example, Teng et al. (2017) used global malmquist luenberger index to measure the carbon productivity of China's service industries.

The above methods belong to the radial and angular DEA model. The relaxation variables or some input or output cannot be reflected in the model. Therefore, Tone (2002) proposed a Super-SBM model based on the SBM models (Tone 2001). The Super-SBM model can evaluate and rank multiple fully effective decision units effectively. Currently, most researchers used the Super-SBM model to measure efficiency. Besides, the above studies mainly focus on the regional level and service level. And, the studies on manufacturing energy carbon emission efficiency in China are relatively few.

The convergence of productivity can be traced back to the neoclassical growth model (slow 1956) and extended to endogenous economic growth theory (Romer 1986). The earliest convergence research is used to test whether there is convergence in the income gap (Baumol 1981). Since then, many scholars have studied the convergence of labor productivity and total factor productivity from the national level, regional level and industrial level respectively (Miller and Upadhyay 2002; Islam 2003; Liu and Zhang 2010; Li et al. 2019;Ji and Xia 2020)

With the increasing harm of carbon emissions to the environment, reducing carbon emissions has become the goal of governments, prompting many scholars to pay attention to the convergence of carbon emissions. For example, Strazicich and List (2003) conducted empirical research with the data of OECE countries, and found that carbon emissions have $\beta$ convergence and stochastic convergence. Westerlund and Basher (2008) studied the convergence of carbon emissions in developed and developing countries, and found that the carbon emissions of these two types of countries have convergence. Xu (2010) examined the convergence of per capita carbon emissions in China and found that there is no $\beta$ absolute convergence, but there is $\beta$ conditional convergence. In addition, the convergence of carbon emission intensity is also concerned by some scholars ( Sun and Zhong 2014; Brannlund et al. 2015; Yu et al. 2018; Huang et al. 2019) .

Increasing carbon productivity is an effective way to reduce carbon emissions, so many scholars began to analyze the evolution trend of carbon productivity and its influencing factors ( $\mathrm{Li}$ and Wang 2019; Liu et al. 2021) . In addition, most scholars focus on the convergence of carbon productivity, mainly at the agriculture level (Gao and song 2015), and service industry level (Teng et al. 2017; Wang et al. 2020). However, a small amount of literature deals with the manufacturing 
level. For example, Yang et al. (2015) found that there were $\sigma$ convergence and $\beta$ convergence in carbon productivity of China's manufacturing from 1998 to 2011.

This study examines the convergence of energy carbon emission efficiency in China. The contributions in this study are as follows: First, this study selects manufacturing as the research object and measure China's manufacturing energy carbon emission, and analyzes its evolution trend. Second, this study accurately measures China's manufacturing energy carbon emission efficiency with the Super-SBM model. Third, this study uses coefficient of variation and convergence model to test the convergence of China's manufacturing energy carbon emission efficiency.

\section{Methodology and data}

\section{Methodology}

To evaluate and rank multiple fully effective decision units effectively (Tone 2002), this paper chooses the Super-SBM model instead of the radial and angular DEA model to calculate the energy carbon emission efficiency. The reason is that Super-SBM model effectively solves the problem of input-output variable relaxation, unexpected output and sorting when multiple decision-making units are effective at the same time. In order to understand Super-SBM model more clearly, this paper first introduces SBM model. Parameters and decision variables of the SBM model are as follows:

$$
\rho=\min \frac{1-\frac{1}{m} \sum_{i=1}^{m} \frac{\overline{s_{i}}}{x_{i 0}}}{1+\frac{1}{s_{1}+s_{2}}\left(\sum_{r=1}^{s_{1}} \frac{s_{r}^{g}}{y_{r 0}^{g}}+\sum_{j=1}^{s_{2}} \frac{s_{j}^{b}}{y_{j 0}^{b}}\right)}
$$

$$
\begin{array}{ll}
\text { s.t. } & x_{0}=X \lambda+S^{-}, y_{0}^{g}=Y^{g} \lambda-S^{g}, y_{0}^{b}=Y^{b} \lambda-S^{b}, \\
& \sum_{i=1}^{n} \lambda_{i}=1, S^{-} \geq 0, S^{g} \geq 0, S^{b} \geq 0, \lambda \geq 0
\end{array}
$$

Parameters and decision variables of the Super-SBM model are as follows:

$$
\rho^{*}=\min \frac{\frac{1}{m} \sum_{i=1}^{m} \frac{\bar{x}_{i}}{x_{i 0}}}{\frac{1}{s_{1}+s_{2}}\left(\sum_{r=1}^{s_{1}} \frac{\bar{y}_{r}^{g}}{y_{r 0}^{g}}+\sum_{j=1}^{s_{2}} \frac{\bar{y}_{j}^{b}}{y_{j 0}^{b}}\right)}
$$

$$
\begin{array}{ll}
\text { s.t. } \quad & \bar{x} \geq \sum_{j=1, \neq 0}^{n} \lambda_{j} x_{j}, y^{-g} \leq \sum_{j=1, \neq 0}^{n} \lambda_{j} y_{j}^{g}, \bar{y}^{-b} \leq \sum_{j=1, \neq 0}^{n} \lambda_{j} y_{j}^{b}, \\
& -\bar{x} \geq x_{0}, y^{-g} \leq y_{0}^{g},{ }^{-b} \geq y_{0}^{b}, \sum_{j=1, \neq 0}^{n} \lambda_{j}=1, y^{-g} \geq 0, \lambda \geq 0
\end{array}
$$

In the formula (1) and formula(2), the model mainly includes target efficiency value $\rho$ and $\rho^{*}$, $x, y^{\mathrm{g}}$ and $y^{b}$ are input, expected output and unexpected output respectively, $S^{-}, S^{g}$ and $S^{b}$ are input slack, expected output slack and unexpected output slack. $m 、 s_{1}$ and $s_{2}$ are the number of input indicators, expected output indicators and unexpected output indicators respectively, and $\lambda$ is the weight vectors. When $\rho^{*} \geq \mathbf{1}$, the evaluated decision unit is effective. According to the Super-SBM model, the calculation of manufacturing energy carbon emission efficiency includes two aspects: output and input. The specific variables are shown in Table 1.

Table 1 Variable and indicator 


\begin{tabular}{|c|c|c|}
\hline $\begin{array}{l}\text { manufacturing expected output } \\
\text { manufacturing non-expected output }\end{array}$ & & $\begin{array}{l}\text { sales manufacturing output value } \\
\text { manufacturing carbon emissions }\end{array}$ \\
\hline manufacturing input & $\begin{array}{l}\text { labor } \\
\text { capital } \\
\text { energy }\end{array}$ & $\begin{array}{l}\text { the number of manufacturing employees } \\
\text { the net value of fixed assets } \\
\text { consumption of total energy }\end{array}$ \\
\hline
\end{tabular}

Manufacturing carbon emissions are mainly produced by fossil fuels. Manufacturing carbon emissions are mainly from eight fossil fuels (IPCC, 2007), including coal, coke, crude oil, gasoline, diesel oil, fuel oil, natural gas, and kerosene. Manufacturing carbon emissions is calculated according to the following formula:

$$
\mathrm{CO}_{2}=\sum_{i=1}^{8} \mathrm{CO}_{2, i}=\sum_{i=1}^{8} E_{i} \times N C V_{i} \times C E F_{i} \times C O F_{i} \times \frac{44}{12}
$$

In the formula, $i$ represents fossil fuels. $\mathrm{CO}_{2}$ represents manufacturing carbon emission. $E$ represents consumption of fossil fuels. $N C V$ represents net calorific value. $C E F$ represents carbon content. $\mathrm{COF}$ represents carbon oxidation factor. The formula on $\mathrm{CO}_{2}$ emission factor of fossil fuels is as follows: $\mathrm{NCV} \times \mathrm{CEF} \times \mathrm{COF} \cdot \mathrm{CO}_{2}$ emission factor of coal, coke, crude oil, gasoline, diesel oil, fuel oil, natural gas, and kerosene is $0.5183,0.7801,0.8237,0.7978,0.8443,0.8647$, $0.5897,0.8231$, respectively (Teng et al. 2017).

$\sigma$ convergence and $\beta$ convergence are the main convergence modes. In this paper, the difference of carbon emission efficiency from the overall average level can be reflected by $\sigma$ convergence. If the gap of carbon emission efficiency of different industries gradually narrows over time, then it has $\sigma$ convergence, otherwise there is no $\sigma$ convergence. $\beta$ convergence is proposed according to the theory of economic convergence, which is divided into absolute $\beta$ convergence and conditional $\beta$ convergence based on whether external factors are considered. Absolute $\beta$ convergence means that the carbon emission efficiency of different industries eventually converges to the same steady-state level over time without controlling external factors. Conditional $\beta$ convergence means that under the premise of controlling external factors, the carbon emission efficiency of different industries eventually converges to their respective steady-state levels over time

Testing method of $\sigma$ convergence. According to Rezitis (2010), the standard deviation and coefficient of variation are used to test whether there is $\sigma$ convergence of carbon emission efficiency. The formula is as follows:

$$
V=S / \bar{C}_{t} ; S=\sqrt{\left[\sum_{i}\left(C_{i t}-\bar{C}_{t}\right)^{2}\right] / N}
$$

In the formula, $i$ represents industry, $t$ represents time, $V$ represents the coefficient of variation, $S$ represents the standard deviation, $C$ represents average carbon productivity in manufacturing, $C$ represents carbon productivity in manufacturing, $N$ represents the number of industry.

Testing method of absolute $\beta$ convergence. According to Bernard and Jones (1996), in this paper, the absolute $\beta$ convergence model of carbon productivity growth in manufacturing is set as follows:

$$
\left(\ln C_{i, t+T}-\ln C_{i, t}\right) / T=\alpha+\beta \ln C_{i, t}+\varepsilon_{i, t}
$$

In the formula, $i$ represents industry, $t$ represents time, $T$ represents the time span, $\ln C$ represents the logarithm of carbon productivity in manufacturing, $\varepsilon$ represents random error term. $\alpha$ and $\beta$ are coefficients to be estimated. If $\beta$ is less than 0 and statistically significant, it means that 
there is absolute $\beta$ convergence of carbon productivity in manufacturing, otherwise, it does not exist. The convergence rate $\sigma=-\frac{1}{T} \ln (1-|\beta|)$.

Testing method of conditional $\beta$ convergence. According to Barro and Sala-i-Martin (1992), in this paper, the conditional $\beta$ convergence model of carbon productivity growth in manufacturing is set as follows:

$$
\left(\ln C_{i, t+T}-\ln C_{i, t}\right) / T=\alpha+\beta \ln C_{i, t}+\gamma X_{i, t}+\varepsilon_{i, t}
$$

In the formula, $x$ represents other factors that affect the growth rate of carbon productivity in manufacturing, the meaning of other variables is consistent with the absolute $\beta$ convergence model. In this paper, $X$ includes industry scale (tis), technology intensity (tie), industry extroversion (tio), institutional quality (tiq). If $\beta$ is less than 0 and statistically significant, it means that there is conditional $\beta$ convergence of carbon productivity in manufacturing, otherwise, it does not exist.

\section{Data}

Based on the panel data of 27 sub-sectors of manufacturing from 2000 to 2016, this paper empirically studies the convergence of manufacturing energy carbon emission efficiency. The sub-sectors of manufacturing are shown in Table 2. To avoid the large bias of results caused by the inconsistent statistical caliber, and part of the data is only updated to 2016, this paper selects the research samples from 2000 to 2016.

The original data is mainly from the statistical yearbook. Consumption of total energy, Consumption of fossil fuels are from China Energy Statistical Yearbook. The sales manufacturing output value, the net value of fixed assets, the number of manufacturing employees are from China Industry Statistical Yearbook. Notably, the sales manufacturing output value is reduced by the producer price indices for manufactured goods, the net value of fixed assets is reduced by the price indices for investment in fixed assets. The price indices are derived from the China Statistical Yearbook and China Price Statistical Yearbook.

Table 2 Sub-sectors of manufacturing

\begin{tabular}{|c|c|c|c|}
\hline Industry & Code & Industry & Code \\
\hline processing of food from agricultural products & C101 & manufacture of medicines & $\mathrm{C} 21$ \\
\hline manufacture of foods & $\mathrm{C} 102$ & manufacture of chemical fibers & $\mathrm{C} 202$ \\
\hline manufacture of beverages & $\mathrm{C} 11$ & manufacture of rubber and plastics products & $\mathrm{C} 22$ \\
\hline manufacture of tobacco & $\mathrm{C} 12$ & $\begin{array}{l}\text { manufacture of non-metallic mineral } \\
\text { products }\end{array}$ & $\mathrm{C} 23$ \\
\hline manufacture of textile & $\mathrm{C} 13$ & smelting and pressing of ferrous metals & $\mathrm{C} 241$ \\
\hline $\begin{array}{l}\text { manufacture of textile, wearing apparel and } \\
\text { accessories }\end{array}$ & $\mathrm{C} 14$ & smelting and pressing of non-ferrous metals & $\mathrm{C} 242$ \\
\hline $\begin{array}{l}\text { manufacture of leather, fur, feather and related } \\
\text { products and footwear }\end{array}$ & $\mathrm{C} 15$ & manufacture of metal products & $\mathrm{C} 25$ \\
\hline $\begin{array}{l}\text { processing of timber, manufacture of wood, } \\
\text { bamboo, rattan, palm, and straw products }\end{array}$ & $\mathrm{C} 16$ & manufacture of general purpose machinery & $\mathrm{C} 281$ \\
\hline manufacture of furniture & $\mathrm{C} 31$ & manufacture of special purpose machinery & $\mathrm{C} 282$ \\
\hline manufacture of paper and paper products & $\mathrm{C} 17$ & manufacture of transport equipment & $\mathrm{C} 29$ \\
\hline
\end{tabular}




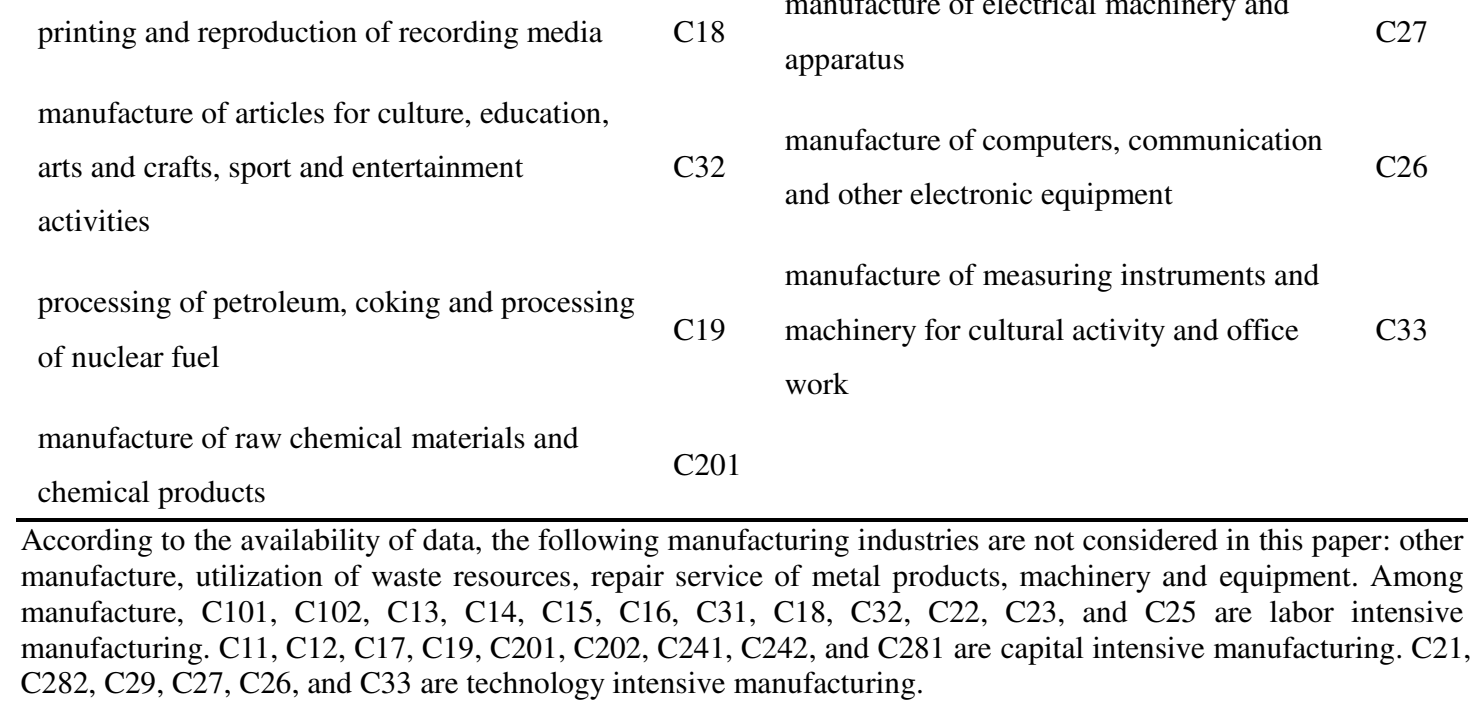

According to the availability of data, the following manufacturing industries are not considered in this paper: other manufacture, utilization of waste resources, repair service of metal products, machinery and equipment. Among manufacture, C101, C102, C13, C14, C15, C16, C31, C18, C32, C22, C23, and C25 are labor intensive manufacturing. C11, C12, C17, C19, C201, C202, C241, C242, and C281 are capital intensive manufacturing. C21, C282, C29, C27, C26, and C33 are technology intensive manufacturing.

\section{Results and discussion}

\section{Results and discussion of manufacturing energy carbon emission}

Manufacturing energy carbon emissions in China from 2000 to 2016 is calculated. The results are shown in Fig. 1, Fig. 2, and Fig. 3.

Fig. 1 displays the gross manufacturing energy carbon emissions in China. From 2000 to 2016, it has demonstrated that China's gross manufacturing energy carbon emissions showed an increasing trend. The carbon emission was about 206071 ten thousand tons in 2000 and 644796 ten thousand tons in 2016. The highest value of the carbon emission was about 653984 ten thousand tons in 2015. Further calculation shows that average annual growth rate of the carbon emission was about 7\%. Further analysis shows that the development trend of total carbon emissions consists of three similar stages. The three stages are from 2000 to 2002,from 2003 to 2008, and from 2009 to 2016, respectively. The above three stages are manifested as the following: Gross manufacturing energy carbon emissions showed an increasing trend. However, the annual growth rate of gross manufacturing energy carbon emissions showed a trend of first increasing and then decreasing. The reason is that on the one hand, Chinese government strengthens the manufacturing carbon emission management; on the other hand, the manufacturing production is increasing. 


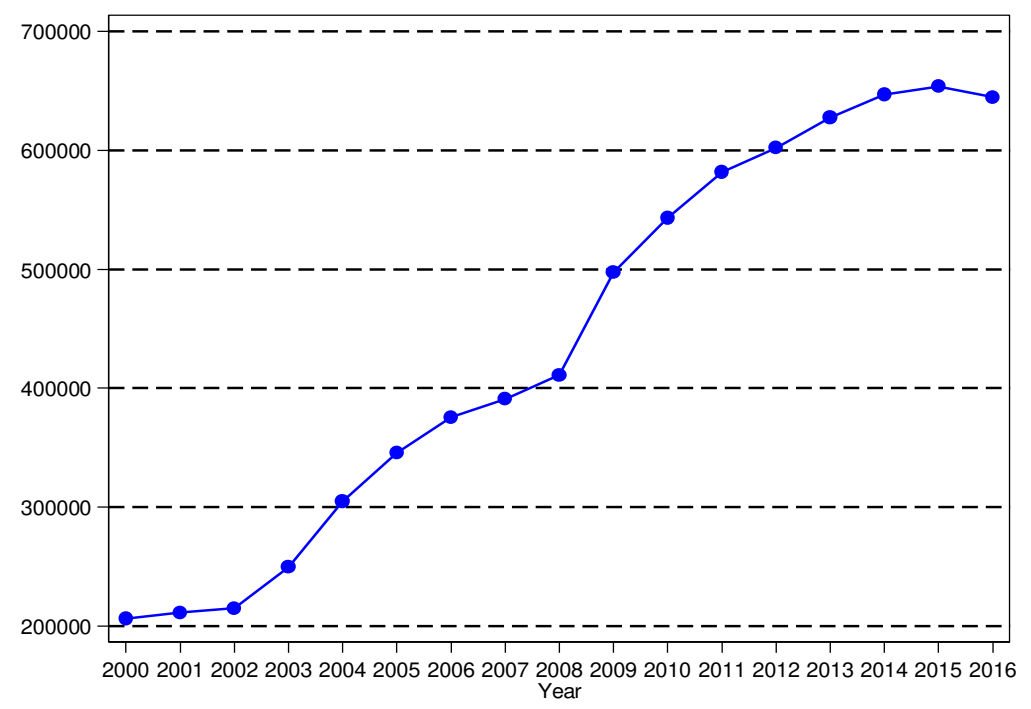

Fig. 1 Gross manufacturing energy carbon emissions.

Fig. 2 illustrates the annual average manufacturing energy carbon emissions in China. It has showed that there were differences in annual energy carbon emissions of manufacturing sub-sectors. The sub-sectors of manufacturing that produce more energy carbon emissions include C19, C241, C201, C23, and C242, which C19 is the highest (about 157,471 ten thousand tons). The sub-sectors of manufacturing that produce less energy carbon emissions include C33, C31, $\mathrm{C} 32, \mathrm{C} 18$, and $\mathrm{C} 12$ are relatively low, which C33 is the lowest (about 126 ten thousand tons). The average annual manufacturing energy carbon emissions of C19 is about 1250 times that of C33. According to the analysis, The sub-sectors of manufacturing with higher energy carbon emissions are mainly distributed in capital intensive industries, while the sub-sectors of manufacturing with lower energy carbon emissions are mainly distributed in labor-intensive industries.

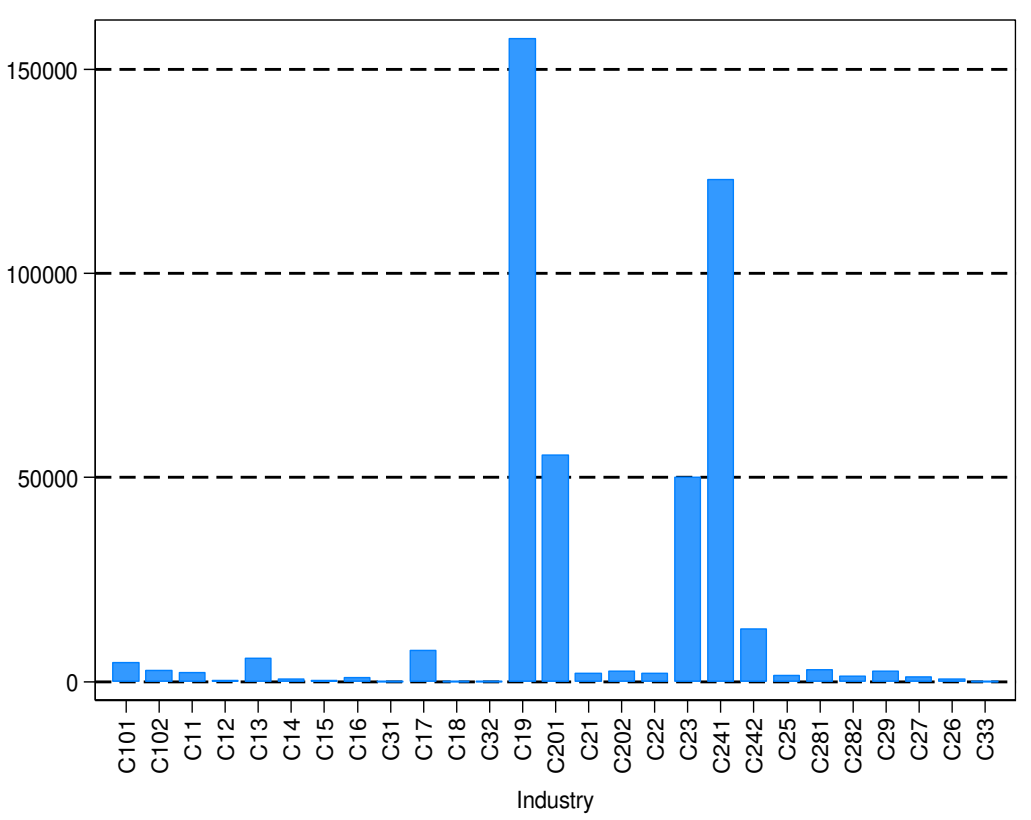

Fig. 2 Annual average manufacturing energy carbon emissions. 
Fig. 3 presents the sources of manufacturing energy carbon emissions in China. It has demonstrated that the major source of China's manufacturing energy carbon emissions was coal. The carbon emissions generated by coal, coke, crude oil, gasoline, diesel oil, fuel oil, natural gas, and kerosene account for about $51.45 \%, 19.08 \%, 24.58 \%, 0.37 \%, 1.01 \%, 1.70 \%, 1.76 \%$, and $0.04 \%$ of total carbon emissions, respectively. Further analysis shows that the proportion of manufacturing energy carbon emissions generated by gasoline, diesel oil, fuel oil, and kerosene has a downward trend, that of natural gas, crude oil, coke, and coal have an upward trend, a "U”-shaped trend, an inverted "U"-shaped trend, and a volatility trend, respectively.

Fig. 3 Sources of manufacturing energy carbon emissions.

\section{Results and discussion of manufacturing energy carbon emission efficiency}

Manufacturing energy carbon emission efficiency in China from 2000 to 2016 is calculated. The results are shown in Fig. 4, Fig. 5.

Fig. 4 displays the evolution trend of manufacturing energy carbon emission efficiency in China. From 2000 to 2016, it has demonstrated that China's manufacturing energy carbon emission efficiency showed an increasing trend. The energy carbon emission efficiency was about 0.1123 in 2000 and reached the highest value of about 0.2452 in 2015 and 0.2378 in 2016 . Further analysis shows that the development trend of energy carbon emission efficiency consists of three stages. The three stages are from 2000 to 2004,from 2005 to 2012, and from 2013 to 2016, respectively. Energy carbon emission efficiency in the first stage and the second stage shows an upward trend. In the above two stages, the annual growth rate of energy carbon emission efficiency showed an increasing trend. However, Energy carbon emission efficiency in the third 


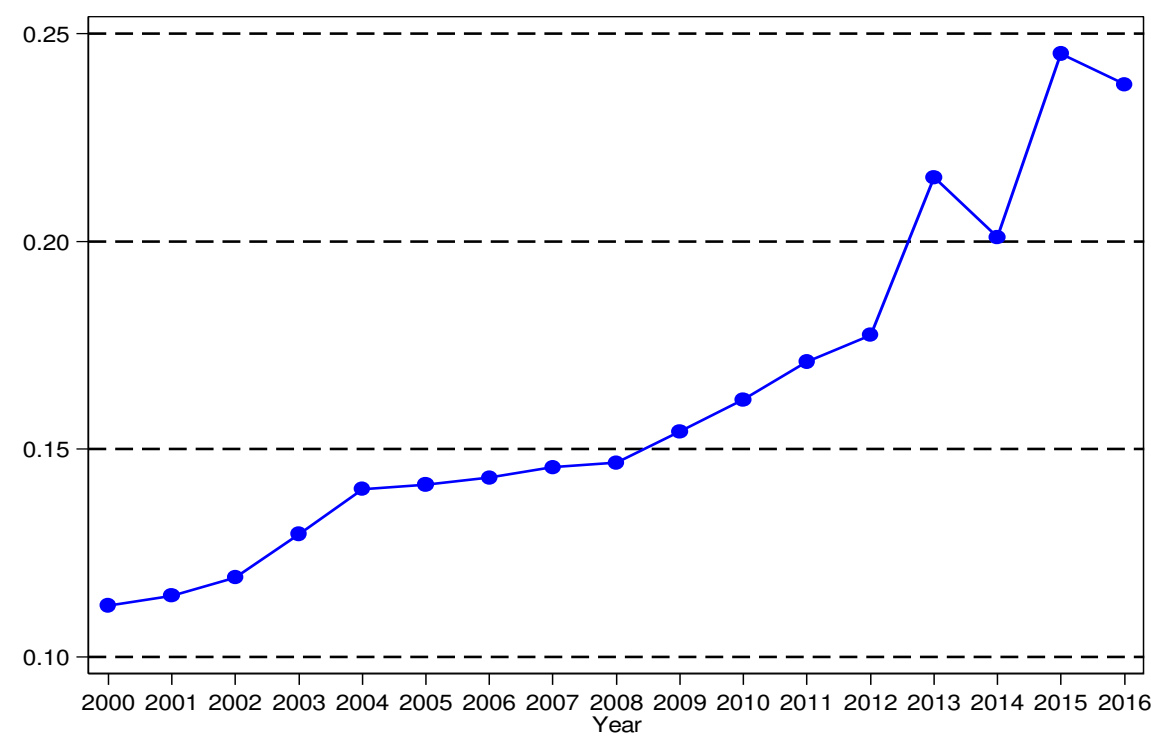

Fig. 4 Evolution trend of manufacturing energy carbon emission efficiency.

Fig. 5 illustrates the annual average manufacturing energy carbon emission efficiency in China. It has showed that there were differences in annual energy carbon emission efficiency of manufacturing sub-sectors. The sub-sectors of manufacturing that owning more annual average manufacturing energy carbon emission efficiency include C19, C12, C241, and C26, which C19 is the highest (about 0.8698). The sub-sectors of manufacturing that owning more annual average manufacturing energy carbon emission efficiency include $\mathrm{C} 25, \mathrm{C} 18, \mathrm{C} 22$, and $\mathrm{C} 33$ are relatively low, which $\mathrm{C} 25$ is the lowest (about 0.0516). The average annual manufacturing energy carbon emission efficiency of C19 is approximately 17 times that of $\mathrm{C} 25$.

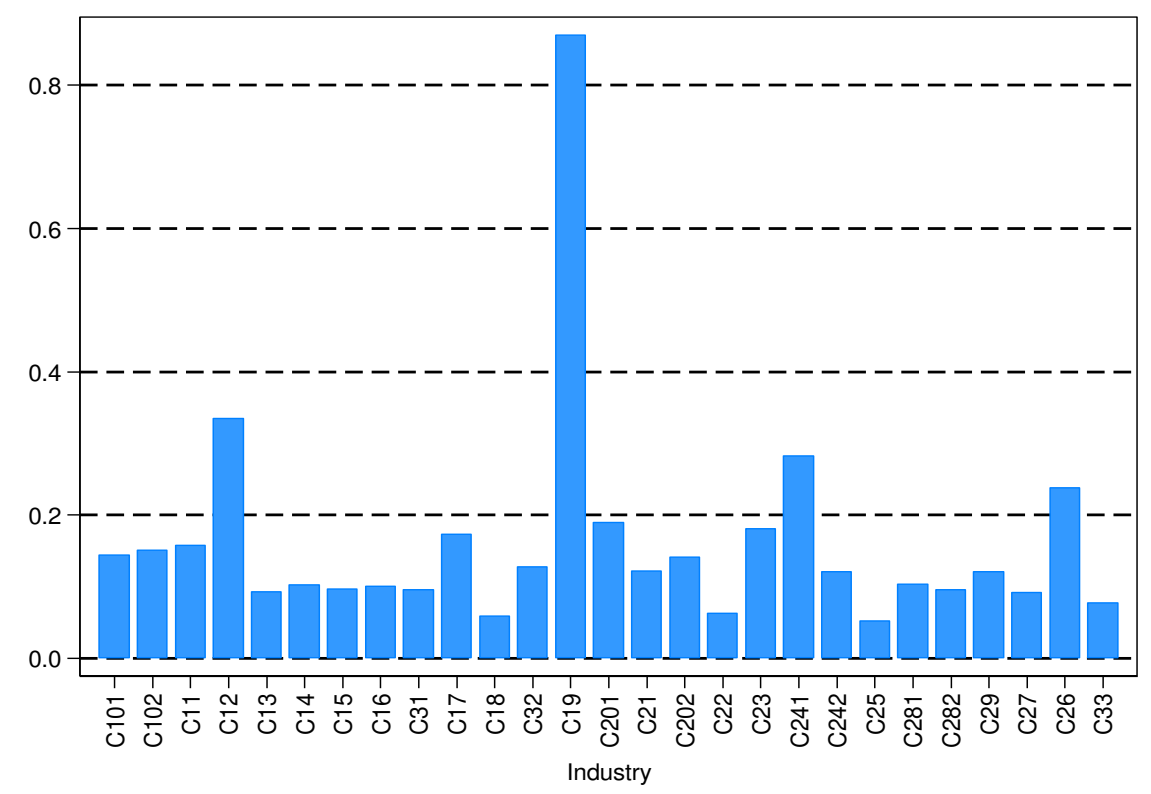

Fig. 5 Annual average manufacturing energy carbon emission efficiency.

Fig. 6 presents the dynamic evolution trend of manufacturing energy carbon emission 
efficiency in China. Kernel density estimation method (Rosenblatt 1956) was used to test dynamic evolution trend of manufacturing energy carbon emission efficiency. According to Fig. 6, The nuclear density map moves to the right over time, and the peak position decreases. Therefore, the manufacturing energy carbon emission efficiency in China is increasing.

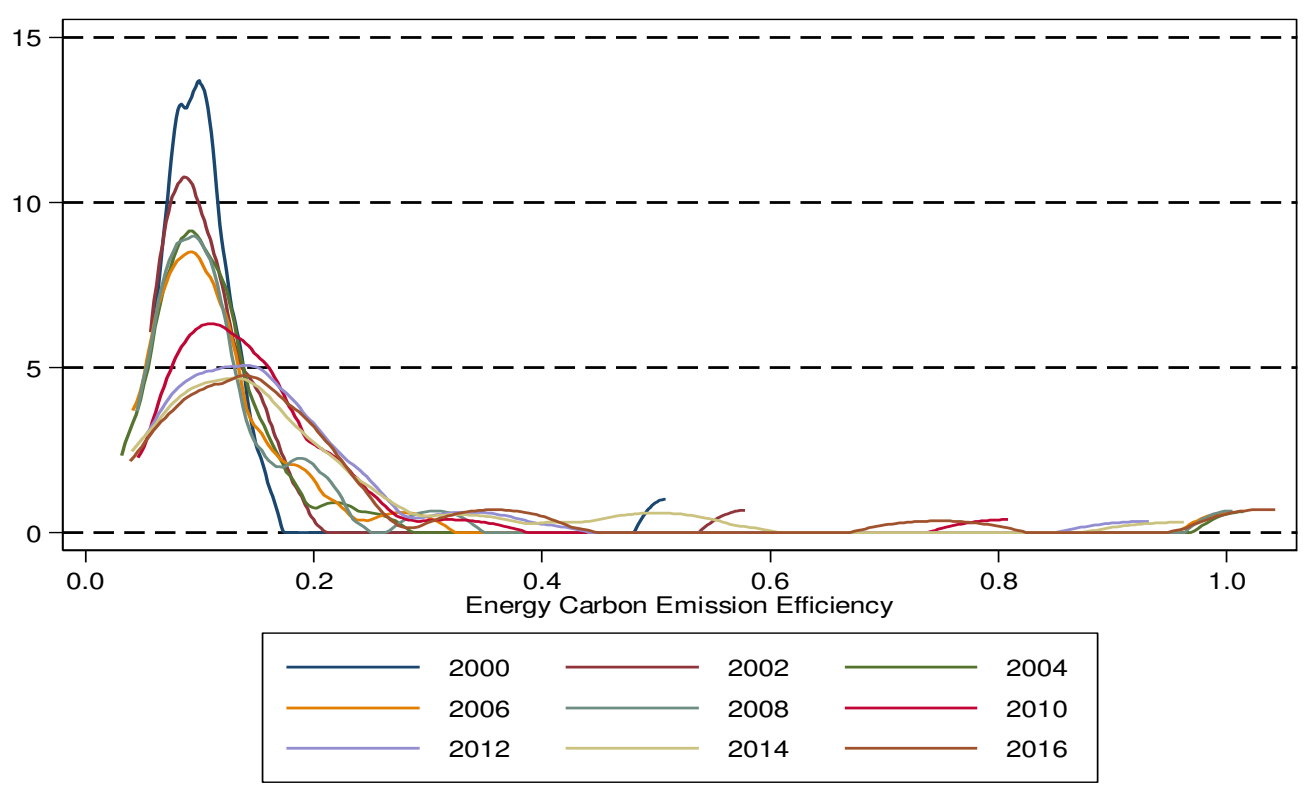

Fig. 6 Dynamic evolution trend of manufacturing energy carbon emission efficiency.

\section{Convergence of manufacturing energy carbon emission efficiency}

The standard deviation and coefficient of variation of manufacturing energy carbon emission efficiency in China from 2000 to 2016 is calculated. The results are shown in Fig. 7.

Fig. 7 displays the evolution trend of the coefficient of variation on manufacturing energy carbon emission efficiency in China. It has demonstrated that there is no $\sigma$ convergence in China's manufacturing energy carbon emission efficiency from 2000 to 2016 . The coefficient of variation on manufacturing energy carbon emission efficiency was about 0.7231 in 2000 and reached the highest value of about 1.2607 in 2004 and 1.1043 in 2016. The coefficient of variation on labor intensive manufacturing energy carbon emission efficiency was about 0.2529 in 2000 and reached the highest value of about 0.6372 in 2016. The coefficient of variation on capital intensive manufacturing energy carbon emission efficiency was about 0.7721 in 2000 and reached the highest value of about 1.1329 in 2004 and 0.8459 in 2016. The coefficient of variation on technology intensive manufacturing energy carbon emission efficiency was about 0.1822 in 2000 and reached the highest value of about 1.2104 in 2015 and 1.2054 in 2016. 


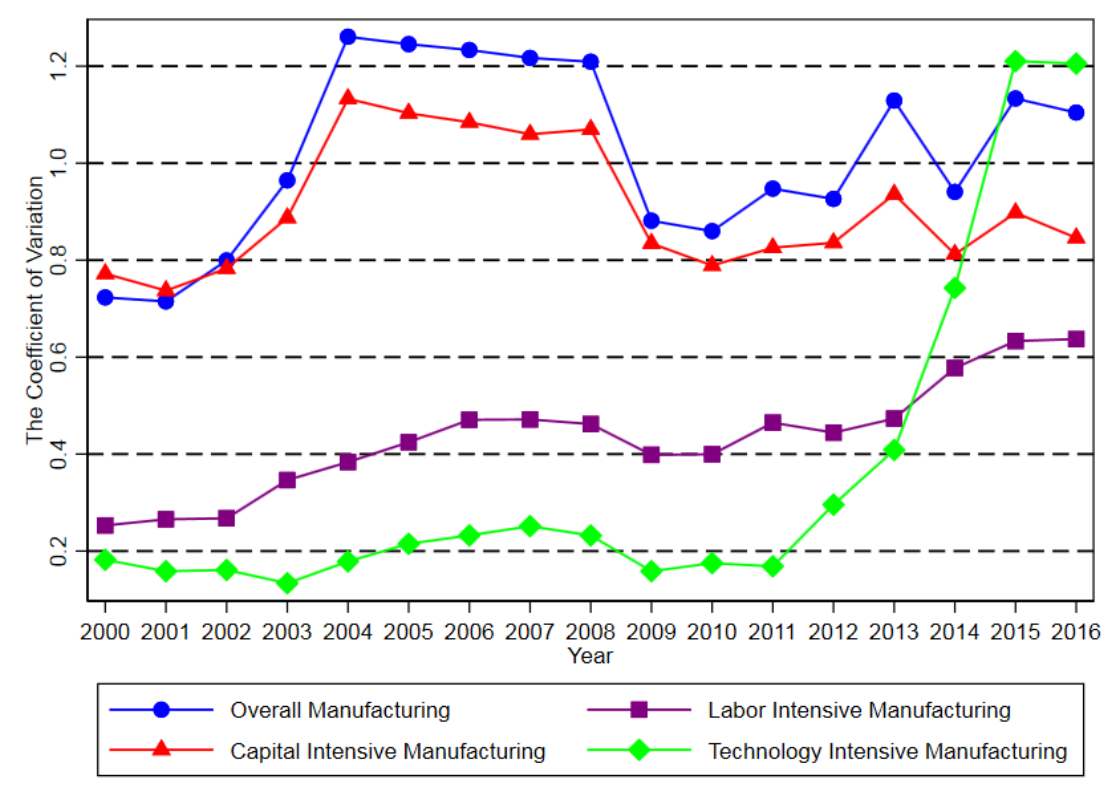

Fig. 7 Evolution trend of the coefficient of variation on manufacturing energy carbon emission efficiency.

The samples of this paper are short panel data and long panel data. For short panel data sample, F test, LM test, Hausman test, and time effect test were used to select the appropriate method. If it does not pass $\mathrm{F}$ test, the POLS model can be used to estimate; otherwise, the appropriate model was selected by Hausman test. If there is no individual effect and it is not passed the Hausman test, RE model should be used. If it passes the F test and Hausman test, time effect test should be used to determine whether to use the two-way FE model. For long panel data sample, Wald test, Wooldridge test, and Pesaran test were used to test whether there were inter groupwise heteroskedasticity, autocorrelation within panel and contemporaneous correlation, respectively. If there is heteroskedasticity or autocorrelation, FGLS should be used. The testing results and the $\beta$ convergence model are estimated. The results are shown in Table 3, Table 4, and Table 5 .

Absolute $\beta$ convergence. Table 3 displays the testing results of absolute $\beta$ convergence on manufacturing energy carbon emission efficiency in China. According to table 3 , there is absolute $\beta$ convergence in manufacturing energy carbon emission efficiency in China. The regression coefficient $\beta$ is -0.0870 , and passes the test of the $1 \%$ significance level. Moreover, the manufacturing industry is divided into three categories of labor intensive manufacturing, capital intensive manufacturing and technology intensive manufacturing. According to table 3 , there is absolute $\beta$ convergence in energy carbon emission efficiency of labor intensive and capital intensive manufacturing in China, but there is no absolute $\beta$ convergence in technology intensive manufacturing. The regression coefficient $\beta$ in labor intensive manufacturing and capital intensive manufacturing is -0.1452 and -0.1239 , respectively, and all passes the test of the $1 \%$ significance levels. The regression coefficient $\beta$ in technology intensive manufacturing is -0.0660 , and has not passed the test of the $10 \%$ significance level. Additionally, labor intensive manufacturing energy carbon emission efficiency in China has the fastest absolute convergence rate. The convergence rate of overall, labor intensive, and capital intensive manufacturing energy carbon emission efficiency in China is $0.57 \%, 0.98 \%$, and $0.83 \%$, respectively. 
Table 3 Absolute $\beta$ convergence

(1)

Overall Labor intensive Capital intensive technology intensive

\begin{tabular}{|c|c|c|c|c|}
\hline & manufacturing & manufacturing & manufacturing & manufacturing \\
\hline \multirow[t]{2}{*}{$\beta$} & $-0.0870 * * *$ & $-0.1452 * * *$ & $-0.1239 * * *$ & -0.0660 \\
\hline & $(0.0295)$ & $(0.0227)$ & $(0.0244)$ & $(0.0591)$ \\
\hline \multirow{2}{*}{ Constant } & $-0.1817 * *$ & $-10.7127 * * *$ & $-10.5096^{* * *}$ & $-13.3633 * *$ \\
\hline & $(0.0736)$ & (2.5559) & (4.0488) & $(5.6824)$ \\
\hline Industry fixed effect & Yes & Yes & Yes & Yes \\
\hline Time fixed effect & Yes & Yes & Yes & Yes \\
\hline F value & $2.78 * * *$ & & & \\
\hline Wald value & & $107.84 * * *$ & $92.12 * * *$ & $14.75^{* *}$ \\
\hline F test & $1.56^{* *}$ & & & \\
\hline LM test & 0.61 & & & \\
\hline Hausman test & $8.4^{* *}$ & & & \\
\hline Time effect test & $2.6 * * *$ & & & \\
\hline Wald test & & $786.09 * * *$ & $2586.81 * * *$ & $328.59 * * *$ \\
\hline Wooldridge test & & $86.105^{* * *}$ & $12.453 * * *$ & 3.386 \\
\hline Pesaran test & & $5.589 * * *$ & 1.593 & 0.002 \\
\hline Observations & 432 & 192 & 144 & 96 \\
\hline R-squared & 0.103 & & & \\
\hline
\end{tabular}

Standard errors in parentheses, $* * * \mathrm{p}<0.01, * * \mathrm{p}<0.05, * \mathrm{p}<0.1$

352

Conditional $\beta$ convergence. Table 4 illustrates the testing results of conditional $\beta$ convergence on manufacturing energy carbon emission efficiency in China. According to table 4, there is conditional $\beta$ convergence in manufacturing energy carbon emission efficiency in China. The regression coefficient $\beta$ is -0.0767 at the $1 \%$ significance level. In addition, manufacturing energy carbon emission efficiency exits scale effect and technology effect, but not the effect of opening to the outside world and institutional effect. The regression coefficient of industry scale (tis) is -0.1102 , and passed the test of the 5\% significance level. The regression coefficient of technology intensity (tie) is 0.9346 , and passed the test of the $1 \%$ significance level. The regression coefficient of industry extroversion (tio), institutional quality (tiq) is 0.0611 and -0.1580 , respectively, and have not passed the test of the $10 \%$ significance level.

Moreover, the manufacturing industry is divided into labor intensive manufacturing, capital intensive manufacturing and technology intensive manufacturing. According to table 4 , there is conditional $\beta$ convergence in energy carbon emission efficiency of labor intensive and capital intensive manufacturing in China, but there is no conditional $\beta$ convergence in technology intensive manufacturing. The regression coefficient $\beta$ in labor intensive manufacturing and capital intensive manufacturing is -0.1419 and -0.1639 , respectively, and all passes the test of the $1 \%$ significance levels. The regression coefficient $\beta$ in technology intensive manufacturing is -0.0955 , and has not passed the test of the $10 \%$ significance level.

Further analysis shows that the labor intensive manufacturing energy carbon emission efficiency exits scale effect, technology effect, effect of opening to the outside world and 
institutional effect. The regression coefficient of tis, tie, tio, and tiq is $0.0948,-0.8947,-0.4635$, and 0.9486 at the $1 \%$ significance level, respectively. The capital intensive manufacturing energy carbon emission efficiency exits scale effect, technology effect and effect of opening to the outside world, but not institutional effect. The regression coefficient of tis, tie, and tio is -0.1036 at the $5 \%$ significance level, 0.5645 at the $1 \%$ significance level, and 1.0979 at the $1 \%$ significance level, respectively. The regression coefficient of tiq is 0.1516 , and have not passed the test of the $10 \%$ significance level. The technology intensive manufacturing energy carbon emission efficiency exits effect of opening to the outside world, but not scale effect, technology effect and institutional effect. The regression coefficient of tio is -0.3150 at the $10 \%$ significance level. The regression coefficient of tis, tie, and tiq is $-0.0661,0.1079$, and 0.1381 , respectively, and have not passed the test of the $10 \%$ significance level.

Additionally, capital intensive manufacturing energy carbon emission efficiency in China has the fastest conditional convergence rate. The convergence rate of overall, labor intensive, and capital intensive manufacturing energy carbon emission efficiency in China is $0.50 \%, 0.96 \%$, and $1.12 \%$, respectively.

Table 4 Conditional $\beta$ convergence

\begin{tabular}{|c|c|c|c|c|}
\hline & $\begin{array}{c}\text { (1) } \\
\text { Overall } \\
\text { manufacturing }\end{array}$ & $\begin{array}{l}\text { (2) } \\
\text { Labor intensive } \\
\text { manufacturing }\end{array}$ & $\begin{array}{l}\text { (3) } \\
\text { Capital intensive } \\
\text { manufacturing }\end{array}$ & $\begin{array}{l}\text { (4) } \\
\text { technology intensive } \\
\text { manufacturing }\end{array}$ \\
\hline$\beta$ & $\begin{array}{c}-0.0767 * * * \\
(0.0295)\end{array}$ & $\begin{array}{c}-0.1419 * * * * \\
(0.0249)\end{array}$ & $\begin{array}{c}-0.1639 * * * \\
(0.0381)\end{array}$ & $\begin{array}{l}-0.0955 \\
(0.0631)\end{array}$ \\
\hline tis & $\begin{array}{c}-0.1102 * * \\
(0.0504)\end{array}$ & $\begin{array}{c}0.0948 * * * \\
(0.0273)\end{array}$ & $\begin{array}{c}-0.1036^{* *} \\
(0.0431)\end{array}$ & $\begin{array}{l}-0.0661 \\
(0.0440)\end{array}$ \\
\hline tie & $\begin{array}{c}0.9346 * * * \\
(0.3460)\end{array}$ & $\begin{array}{c}-0.8947 * * * \\
(0.1638)\end{array}$ & $\begin{array}{c}0.5645 * * * \\
(0.2089)\end{array}$ & $\begin{array}{c}0.1079 \\
(0.2673)\end{array}$ \\
\hline tio & $\begin{array}{c}0.0611 \\
(0.1679)\end{array}$ & $\begin{array}{c}-0.4635 * * * \\
(0.1281)\end{array}$ & $\begin{array}{c}1.0979 * * * \\
(0.3945)\end{array}$ & $\begin{array}{l}-0.3150 * \\
(0.1618)\end{array}$ \\
\hline tiq & $\begin{array}{l}-0.1580 \\
(0.3353)\end{array}$ & $\begin{array}{c}0.9486 * * * \\
(0.1006)\end{array}$ & $\begin{array}{c}0.1516 \\
(0.2044)\end{array}$ & $\begin{array}{c}0.1381 \\
(0.2558)\end{array}$ \\
\hline Constant & $\begin{array}{c}0.4230 \\
(0.4168)\end{array}$ & $\begin{array}{c}45.3166^{* * *} \\
(7.2416)\end{array}$ & $\begin{array}{c}-52.7508 * * * \\
(12.0755)\end{array}$ & $\begin{array}{l}-32.6044 * \\
(18.3254)\end{array}$ \\
\hline Industry fixed effect & Yes & Yes & Yes & Yes \\
\hline Time fixed effect & Yes & Yes & Yes & Yes \\
\hline F value & $2.79 * * *$ & & & \\
\hline Wald value & & $290.91 * * *$ & $84.34 * * *$ & $29.24 * * *$ \\
\hline F test & $1.62 * *$ & & & \\
\hline LM test & 0.01 & & & \\
\hline Hausman test & $18.62 * * *$ & & & \\
\hline Time effect test & $2.87 * * *$ & & & \\
\hline Wald test & & $608.11 * * *$ & $1906.88 * * *$ & $381.98 * * *$ \\
\hline Wooldridge test & & $45.127 * * *$ & $11.525^{* * *}$ & 3.011 \\
\hline Pesaran test & & $3.665 * * *$ & 1.614 & 0.641 \\
\hline Observations & 432 & 192 & 144 & 96 \\
\hline
\end{tabular}


Robustness test. In order to further test the robustness of the regression results, considering the impact of the financial crisis in 2008, this paper tests the convergence of the samples from 2000 to 2008 and from 2009 to 2016 . Table 5 presents the robustness test of regression results. According to table 5, the regression results are robust. There are absolute $\beta$ convergence and conditional $\beta$ convergence in manufacturing energy carbon emission efficiency in China from 2000 to 2008 and from 2009 to 2016 . The regression coefficient $\beta$ is negative from 2000 to 2008 and from 2009 to 2016, and passes the test of the $1 \%$ significance level.

Table 5 Robustness test of regression results

\begin{tabular}{lcccc}
\hline \multicolumn{2}{c}{$2000-2008$} & \multicolumn{2}{c}{$2009-2016$} & $(4)$ \\
\hline$\beta$ & $(1)$ & $(2)$ & $-0.2077 * * *$ & $-0.2594 * * *$ \\
& $-0.2626^{* * *}$ & $-0.2481^{* * *}$ & $(0.0508)$ & $(0.0594)$ \\
Control & $(0.0405)$ & $(0.0453)$ & NO & YES \\
Constant & NO & YES & $-0.3675^{* * *}$ & -0.1637 \\
& $-0.5780^{* * *}$ & $-0.9602^{* *}$ & $(0.0992)$ & $(0.9624)$ \\
Industry fixed effect & $(0.0912)$ & $(0.3935)$ & Yes & Yes \\
Time fixed effect & Yes & Yes & No & No \\
F value & No & No & $16.70 * * *$ & $4.12 * * *$ \\
F test & $42.12^{* * *}$ & $8.57 * * *$ & $2.28 * * *$ & $1.96^{* * * *}$ \\
LM test & $3.36^{* * *}$ & $2.90^{* * * *}$ & 1.34 & 0.21 \\
Hausman test & 0.00 & 0.23 & $18.70^{* * *}$ & $24.96^{* * *}$ \\
Time effect test & $44.11^{* * *}$ & $42.53 * * *$ & 1.49 & 1.51 \\
Observations & 0.30 & 0.69 & 189 & 189 \\
R-squared & 216 & 216 & 0.094 & 0.116 \\
\hline
\end{tabular}

Standard errors in parentheses, ${ }^{* * *} \mathrm{p}<0.01,{ }^{* *} \mathrm{p}<0.05,{ }^{*} \mathrm{p}<0.1$

\section{Conclusion and policy implications}

Based on the panel data of China's manufacturing, this paper measures and analyzes the evolution trend of manufacturing carbon emission and energy carbon emission efficiency. On this basis, this paper uses coefficient of variation and convergence model to test the convergence of China's manufacturing energy carbon emission efficiency. The main conclusions are as follows: First, China's gross manufacturing energy carbon emissions shows an increasing trend from 2000 to 2016. There were differences in annual energy carbon emissions of manufacturing sub-sectors, and the coal was the main source. Second, China's manufacturing energy carbon emission efficiency increased from 2000 to 2016 . There were differences in annual energy carbon emission efficiency of manufacturing sub-sectors. there is no $\sigma$ convergence in China's manufacturing energy carbon emission efficiency from 2000 to 2016. There is absolute $\beta$ convergence and conditional $\beta$ convergence in manufacturing energy carbon emission efficiency in China, and its convergence exists industry heterogeneity. Third, manufacturing energy carbon emission efficiency exits scale effect and technology effect, but not the effect of opening to the outside 
world and institutional effect, and its effect exists industry heterogeneity.

Based on the above research conclusion, the following policy implications are obtained: First, China should implement the clean production action of manufacturing industry and carry out the pilot project of green energy replacing fossil energy such as coal, so as to reduce carbon emissions. Meanwhile, China should strengthen the carbon emission control of the manufacturing industry, optimize the energy consumption structure, establish different supervision of fossil energy production for different industries, and advocate enterprises to strictly implement green energy policies and fossil energy access management. Second, for capital intensive industries and labor-intensive industries, China should carry out technological transformation, and accelerate the narrowing of the energy carbon emission efficiency gap between industries. For technology intensive industries, China should actively guide them to adopt clean energy policies, achieve a higher level of energy carbon emission efficiency, and drive the development of other industries, so as to realize the balanced development of the industry. Third, to improve the energy and carbon emission efficiency, China's manufacturing should make rational use of industry resources, appropriately adjust the industry scale, promote the industry to obtain economies of scale, increase $R \& D$ investment, enhance technology intensity, and promote the upgrading of manufacturing industry to innovation driven.

Acknowledgements The authors thank the editors and reviewers.

Availability of data and material Not applicable.

Author contribution All authors; Dr. Dongdong Liu contributed to this study.

Funding This work is funded by the National Philosophy and Social Science Foundation of China, China (Key Project Grant No. 19XJL006).

\section{Declarations}

Ethics approval and consent to participate Not applicable.

Consent for publication Not applicable.

Competing interests The authors declare no competing interests.

\section{References}

Barro RJ, Sala-i-Martin X (1992) Convergence. J Polit Econ 100(2):223-251

Baumol WJ (1986) Productivity growth, convergence, and welfare: what the long-run data show. Am Econ Rev 76(5):1072-1085

Bernard AB, Jones CI (1996) Comparing apples to orange: productivity convergence and measurement across industries and countries. Am Econ Rev 86(5):1216-1238

Brannlund R, Lundgren T, Soderholm P (2015) Convergence of carbon dioxide performance across Swedish industrial sectors: an environmental index approach. Energy Econ 51:227-235 
Cheng LL, Zhang JB, Tian Y, Zhou XS (2016) The spatial variation characteristics and dependency of agricultural carbon productivity in China. Resour Sci 38(2):276-289

Chung YH, Färe R, Grosskopf S (1997) Productivity and undesirable outputs: a directional distance function approach. J Environ Manage 51 (3):229-240

Dong B, Ma X, Zhang Z, et al (2020) Carbon emissions the industrial structure and economic growth: evidence from heterogeneous industries in China. Environ Pollut 262: 114322

Farrell MJ (1957) The Measurement of productive efficiency. J R Stat Soc 120(3):253-290

Gao M, Song HY (2015) Dynamic changes and spatial agglomeration analysis of the Chinese agricultural carbon emissions performance. Econ Geogr 35(4):142-148

Hernández-Sancho F, Molinos-Senante M, Sala-Garrido R (2011) Energy efficiency in Spanish wastewater treatment plants: a non-radial DEA approach. Sci Total Environ 409(14):2693-2699

Huang JB, Liu CH, Chen SX, et al (2019) The convergence characteristics of China's carbon intensity: Evidence from a dynamic spatial panel approach. Sci Total Environ 668:685-695

IPCC (2007) Climate change 2007: mitigation: contribution of working group III to the fourth assessment report of the intergovernmental panel on climate change: summary for policymakers and technical summary. Cambridge University Press

Islam N (2003) Productivity dynamics in a large sample of countries: a panel study. Rev Income Wealth 49(2) :247-272

Ji CJ, Xia HM (2020) Study on the impact of agricultural science and technology service on agricultural green total factor productivity in China. Chinese J Agr Resour Regional Plan 41(12):136-143

Li JK, Ma JJ, Wei W (2020) Study on regional differences of energy carbon emission efficiency in eight economic areas of China. J Quant Tech Econ Res 37(6):109-129

Li QN, Li GC, Gao X, Yin CJ (2019) Analysis of regional gap and spatital convergence of agricultural total factor productivity growth Chinese. J Agr Resour Regional Plan 40(7):28-36

Li SJ, Wang Sj (2019) Examining the effects of socioeconomic development on China's carbon productivity: a panel data analysis. Sci Total Environ 659:681-690

Liu DD, Zhu XY, Wang YF (2021) China's agricultural green total factor productivity based on carbon emission: an analysis of evolution trend and influencing factors. J Clean Prod 278:1-12

Liu XK, Zhang C (2010) The total factor productivity growth and convergence analysis for China's service industry. J Quant Tech Econ Res 27(3):55-67

Miller SM, Upadhyay MP (2002) Total factor productivity and the convergence hypothesis. J Macroecon 24(2) :267-286

Oh D (2010) A global Malmquist Luenberger productivity index. J Prod Anal 34(3):183-197

Pretis F, Roser M (2017) Carbon dioxide emission-intensity in climate projections: comparing the observational record to socio-economic scenarios. Energy 135:718-725

Rezitis AN (2010) Agricultural productivity and convergence: Europe and the United States. Appl Econ 42(8):1029-1044

Romer PM (1986) Increasing returns and long-run growth. J Polit Econ 94(5):1002-1037

Rosenblatt M (1956) Remarks on some nonparametric estimates of a density function. Ann Math Stat 27 (3): $832-837$

Solow R (1956) A contribution to the theory of economic growth. Q J Econ 70(1):65-94

Strazicich MC, List JA (2003) Are $\mathrm{CO}_{2}$ emission levels converging among industrial countries. Environ Resour Econ 24(3):263-271

Sun YH, Zhong WZ (2014) Provincial convergence of carbon emissions intensity in China: a spatial panel 
approach. Econ Manage 36(12):31-40

Teng ZW, Hu Zb, Jiang XY (2017) Study on the difference and convergence of carbon productivity in China's service industry. J Quant Tech Econ Res 34(3):78-94

Tone KA (2002) Slacks-based measure of super-efficiency in data envelopment analysis. Eur J Oper Res 143 (1): $32-41$

Tone KA (2001) Slacks-based measure of efficiency in data envelopment analysis. Eur J Oper Res 130(3):498-509

Wang XL, Wang SL, Teng ZW (2020) Research on spatial convergence of carbon productivity in China's service industry. China Popul Resour Environ 30(2):70-79

Watanabe M, Tanaka K (2007) Efficiency analysis of Chinese industry: a directional distance function approach. Energy Policy 35(12):6323-6331

Westerlund J, Basher SA (2008) Testing for convergence in carbon dioxide emissions using a century of panel data. Environ Resour Econ 40(1):109-120

Wu XH, Li L (2014) The differences and enhancing potential of provincial carbon productivity and energy efficiency. Econ Geogr 34(5):105-108

Xie HQ, Huang LY, Liu DD (2018) Does GVC participation increase Chinese manufacturing's carbon productivity J Int $\operatorname{Tr}(12): 109-121$

Xu GY (2010) The convergence in carbon dioxide emissions: theoretical hypotheses and empirical research in China. J Quant Tech Econ Res 27(9):31-42

Yang X, Li XP, Zhou DC (2015) Study on the difference and convergence of carbon productivity in Chinese manufacturing. J Quant Tech Econ Res 32(12):3-20

Yu SW, Hu X, Fan JL, Cheng JH (2018) Convergence of carbon emissions intensity across Chinese industrial sectors. J Clean Prod 194:179-192

Zhao HR, Guo S, Zhao HR (2019) Provincial energy efficiency of China quantified by three-stage data envelopment analysis. Energy 166:96-107

Publisher's note Springer Nature remains neutral with regard to jurisdictional claims in published maps and institutional affiliations. 